\title{
Çizgi Film ve Fantastik Animasyonlardaki Karakterlerinin Bağımlılık Kapsamında Analizi ve Çocuklar Üzerindeki Etkisi
}

\author{
Analysis of Characters in Cartoons and Fantasy Animations within the Scope of \\ Addiction and its Effect on Children
}

(D) Abdullah SARMAN ${ }^{1}$, (1) Emine SARMAN²

${ }^{1}$ Bingöl Üniversitesi, Sağlık Hizmetleri Meslek Yüksekokulu, Tıbbi Hizmetler ve Teknikler Bölümü, İlk ve Acil Yardım Programı, Bingöl, Türkiye

${ }^{2}$ Süleyman Demirel Üniversitesi, Tıp Fakültesi, Isparta, Türkiye

\section{Öz}

Çocukların en sevdiği programlar olarak bilinen çizgi filmler, fantastik animasyonlardaki karakterler, hayatlarının ilk günlerinden itibaren sürekli olarak deneyimledikleri programlar ve karakterler arasındadır. Çünkü çocukların kurgusal dünyaları vardır ve bu tür içerikler kendilerine cazip gelmektedir. Bu durum onların masal dinlemekten, çizgi film izlemekten ve video oyunları oynamaktan hoşlanmalarına neden olmaktadır. Çocukların çizgi filmleri ve fantastik animasyonlardaki karakterleri takip etme nedenleri hala tartışılsa da yaygın görüş çocukların fantastik durumlar ve gerçek arasında tam bir ayrım yapamamalarından kaynaklandığıdır. Fantastik animasyonlardaki karakterlerin veya kahramanlarının gerçek olduğunu düşünmek çocukların fantastik olaylara olan inancını etkileyerek küçük çocukların gelişimini, davranışlarını ve günlük aktivitelerini etkileyebilir. Ortaya çıkabilecek sorunlar, erken dönemde tespit edilerek gereken önlemler alınmadığında problemlerin yetişkinliğe kadar devam edebileceği belirtilmektedir. Bu derleme makalede, çizgi film ve fantastik animasyonlardaki karakterlerin bağımlılık kapsamında analizi ve çocuklar üzerindeki etkilerinin bilișsel, fiziksel, sosyal ve duygusal gelișim kapsamında değerlendirilmesi amaçlanmıștır. Konuyla ilgili alanyazında belirtilen verilerin bütünleștirilmesi ve elde edilen bilgiler çerçevesinde birtakım önerilerde bulunulması hedeflenmiştir.

Anahtar kelimeler: Animasyon, çizgi film, çocuk, fantastik karakter

\section{Abstract}

Cartoons known as children's favorite programs, characters in fantastic animations are among the programs and characters that they experience continuously from the first days of their lives. Because children have fictional worlds and such content appeals to them. This causes them to enjoy listening to fairy tales, watching cartoons, and playing video games. Although the reasons for children to follow the characters in cartoons and fantasy animations are still debated, the common view is that children do not fully distinguish between fantastic situations and reality. Thinking that characters or heroes in fantasy animations are real can affect children's belief in fantastic events, affecting the development, behavior and daily activities of young children. It is stated that problems that may arise can continue until adulthood when the necessary precautions are not taken by detecting them in the early period. In this review article, it is aimed to analyze the characters in cartoons and fantastic animations within the scope of addiction and to evaluate their effects on children within the scope of cognitive, physical, social and emotional development. It is aimed to integrate the data specified in the literature on the subject and to make some suggestions within the framework of the information obtained.

Keywords: Animation, cartoon, child, fantastic character

Yazıșma Adresi/Address for Correspondence: Abdullah SARMAN, Bingöl Üniversitesi, Sağıı Hizmetleri Meslek Yüksekokulu, Tıbbi Hizmetler ve Teknikler Bölümü, Illk ve Acil Yardım Programı, Bingöl, Türkiye

E-posta: asarman@bingol.edu.tr

ORCID ID: 0000-0002-5081-4593
Geliș Tarihi/Received: 31.08.2021

Kabul Tarihi/Accepted: 13.10.2021 


\section{Giriş}

Güncel bilimsel literatürde, küçük çocukların gerçek ve hayal arasındaki ince çizgide tam bir netliğe sahip olmadıkları belirtilmiștir (1). Bu iddia 1929 yılında ilk kez Piaget tarafından dillendirilmiş̧ir. Piaget, çocukların bu ayrımı 12 yaşına kadar kesin olarak yapamadığını savunarak fantezi, illüzyon gibi gerçek dıșı olay ve durumları tam olarak kavrayamadıklarını ve gerçeklikle karıștırdıklarını belirtmiștir. Bu durumu örneklendiren Piaget, çocukların ejderhaları ve hayalet kılığına giren birini izlediklerinde, onların gerçekten bir ejderha veya hayalet olup olmadığı konusunda kafalarının karışık olacă̆ını ifade etmiștir (2). Bu yönüyle değerlendirildiğinde gerçek ötesi fantastik varlıklara inanma eğilimi, araştırmacıların ilgisini çeken, medyada da sıklıkla ișlenen popüler bir konu haline gelmiş̦tir (3).

Çocukların en sevdiği programlar olarak bilinen çizgi filmler, fantastik animasyonlardaki karakterler, hayatlarının ilk günlerinden itibaren sürekli olarak deneyimledikleri programlar ve karakterler arasındadır (4). Çünkü çocukların kurgusal bir dünyası vardır ve bu tür içerikler kendilerine cazip gelmektedir. Bu durum onların masal dinlemekten, çizgi film izlemekten ve video oyunları oynamaktan hoșlanmalarına da neden olmaktadır (1). Bu gerçeği belirten çalışmalar çocukların televizyon, dizüstü bilgisayar, akıllı telefon ve tablet gibi araçları hayatları boyunca sık olarak kullandığını ve yașamlarının önemli bir bölümünü ekran başında geçirdiğini ortaya koymuştur (5). Bazı çalışmalar ise bu araçların kullanım yaygınlığını belirlemeyi amaçlamıştır. Örneğin, televizyonda çizgi film izleyenlerin yaş aralı̆̆ının değişmekle birlikte 2-7 yaş grubunda daha yaygın olduğu belirlenmiștir (6). Ülkemizde yapılan araştırmaların benzer sonuçlar ortaya koyduğu görülmüștür. Öztürk ve Karayağız Muslu tarafından anaokuluna giden, yaş aralı̆̆ı 3-6 olan çocukların televizyon izleme durumları ve etkileyen faktörlerin belirlenmesi amacıyla yapılan kesitsel-tanımlayıcı araştırmada, çocukların $\% 47,8^{\prime}$ inin günlük olarak iki saat ve üzerinde televizyon izledikleri belirlenmiștir (7). Erdoğan ve Baran (4), Gündüz Kalan (8) tarafından yapılan araștırmaların sonuçları incelendiğinde ise 6 yaşındaki çocuklarda günlük televizyon izleme süresinin 2-4 saat olduğu ve seyredilen programların genelini çizgi filmlerin oluşturduğu belirlenmiștir. Çocukların çizgi filmleri ve fantastik animasyonlardaki karakterleri takip etme nedenleri hala tartışıısa da yaygın görüș çocukların fantastik durumlar ve gerçek arasında tam bir ayrım yapamamalarından kaynaklandığıdır (9).

Çocuklar çizgi filmler yardımıyla gördüklerini taklit etmeye başlar ve bir anlamda dış dünyayı anlamlandırmaya çalışır (10). Ayrıca çizgi filmler, çocukların doğru veya yanlış konusundaki fikirlerinin olușmasında etkili olmaktadır (11). Aslında çocuklar hangi olayların gerçek olduğunu, hangilerinin olmadı̆̆ını doğru bir şekilde belirtebilme konusunda yeteneklidir (12). Fakat yapılan araştırmalar, çocukların fantastik olaylarla gerçek yașam arasındaki farkı ayırt etme yetkinliğinin duygusal uyarıcılarla değiştiğini göstermiş̧tir. Örneğin yaş aralığı 4-7 olan çocuklardan boş kutuların içinde olumlu veya olumsuz varlıklar (köpek yavrusu, canavar vb.) hayal etmeleri istendiğinde, olumlu varlıkları içeren kutulara yaklaşmaları, olumsuz varlıkları içeren kutulardan kaçınmaları, çocukların duygusal tepkilerinin, varlıkların gerçek olduğuna dair inançlarıyla ilişkili olduğunu göstermektedir $(13,14)$. Bununla birlikte, diğer araștırmalarda, yaş aralı̆ı 3-5 olan çocukların korku unsuru içeren fantastik ve gerçek olayların görüntülerini değerlendirmeleri istendiğinde fantastik olayların gerçek olmadığını düşündüklerini belirttikleri görülmüştür (15). Fantastik animasyonlardaki karakterlerin veya kahramanlarının gerçek olduğunu düşünmek çocukların fantastik olaylara olan inancını etkileyerek, birtakım sorunlara da neden olabilir. Yapılan bu tür araştırma sonuçları birlikte değerlendirildiğinde çocukların fantastik olaylar ve gerçek durumları değerlendirme şekillerinin farklılık gösterdiğini, ancak duyguların çocuk üzerindeki etkisinin nereden kaynaklandığının açıkça belgelenemediğini ortaya çıkmaktadır (16).

Çevresini taklit eden ve hayatı anlamlandırmaya çalışan çocuk için izlediği çizgi filmler etkili bir öğreticidir. Çocuklar, televizyon, dizüstü bilgisayar, akıllı telefon ve tabletlerden görerek ve ișiterek, nesne ve olayları hareketli olarak öğrenme fırsatı yakalayabilirler. Bunun doğal bir sonucu olarak da çizgi film kahramanlarıyla kendileri arasında bir özdeșim kurarlar (17). Çizgi film dünyasının fantastik kahramanlarının birtakım üstün güç ve nitelikleriyle kötülerle savașması, dünyayı kurtarma misyonu üstlenmesi çocuklara cazip gelmekte ve onları etkilemektedir (18).

Bu derleme makalede, çizgi film ve fantastik animasyonlardaki karakterlerin bağımlılık kapsamında analizi ve çocuklar üzerindeki etkilerinin bilişsel, fiziksel, sosyal ve duygusal gelișim kapsamında değerlendirilmesi amaçlanmıştır. Konuyla ilgili alanyazında belirtilen verilerin bütünleștirilmesi ve elde edilen bilgiler çerçevesinde birtakım önerilerde bulunulması hedeflenmiștir.

\section{Karakterlerin Çocukların Bilişsel ve Fiziksel Gelişimine Etkisi}

Televizyon ve çizgi filmlerin çocukların bilișsel gelişimi üzerindeki etkisi kırk yılı aşkın bir süredir araştırılmakta ve çelişkili sonuçlar ortaya çıktığı belirtilmektedir. Literatürdeki bazı çalıșmalar çocuklarda bilişsel gelişimi ve davranışları desteklediğini, faydalı olduğunu (19), bazıları ise çocukların dikkatini azaltarak, dil gelișimini olumsuzetkilediğini göstermiștir (20). Bilișsel süreçlerin bu tür içeriklerin izlenmesinden ne ölçüde etkilendiği de hala tartışılmaktadır. Christakis ve arkadaşları (21), izlemeye harcanan zamanın ve belirli türden içeriğe maruziyetin çocukların dikkatini olumsuz yönde etkilediğini, davranışsal kontrol sorunlarının meydana gelme riskini arttırdı̆̆ını göstermiștir. Nathanson 
ve arkadaşlarının (22), dört yaşındaki çocukların televizyon izlemeye bașlama yașı, izlediği kanallar ve içerikleriyle yürüme becerileri, dil gelişimi, uyku düzeyleri arasındaki ilişkiyi incelediği araștırmada daha küçük yașta televizyon izlemeye bașlayan ve çok fazla televizyon izleyen çocukların yürüme ișlevleri ve dil gelişiminin daha zayıf olduğu belirlenmiștir. Ayrıca çizgi filmlerin, çocuklardaki bazı gelişimsel performansları olumsuz yönde etkilediği belirtilmiștir. Shin'in (23), yaptığı araștırmada ise orta çocukluk döneminde televizyon ve çizgi film izleme miktarının akademik performans üzerindeki doğrudan ve dolaylı zararlı etkileri incelenmiş bu tür içerikleri izlemenin öğrenmeye yardımcı olmadığı, tam tersine zihinsel tembellik meydana getirdiği ve dikkati sürdürme yeteneğini azalttığı belirlenmiștir. Yapılan son çalışmalarda ise, yaşa uygun eğitim içeriklerini izlemenin potansiyel faydaları olduğu vurgulanmaktadır. Örneğin Baydar ve arkadașlarının (24), çalıșmasında okul öncesi dönemdeki çocuklarda öğrenmeyi pekiștirmek için tasarlanmış çizgi film programlarının çocukların matematik ve okuryazarlık becerilerini geliştirdiği belirlenmiștir. Benzer şekilde Roberts ve arkadaşlarının (25), çalıșmasında televizyon ve çizgi film izleme süresiyle ilkokul çocuklarının okuma becerileri arasındaki ilișki araștırılmıștır. Televizyon izleme süresinin okuma becerisi üzerinde ikinci, üçüncü ve altıncı sınıftaki çocuklarda olumlu yönde anlamlı bir etkiye neden olabildiği belirlenmiștir. Çocukların okuma yeteneklerinin televizyon izleme süresiyle arttığı, öğrenme faaliyetlerindeki motivasyonu sağlamak için televizyondaki çizgi film gibi programların kullanılabileceği belirtilmiştir. Tüm bu tutarsızlıklara rağmen, metodolojik olarak sağlam bir dizi deneysel çalıșma tarafından desteklenen bol miktarda korelasyonel kanıt, çocukların çizgi film izlemesiyle meydana gelebilecek gelișimsel sonuçlar arasındaki temel ilișkileri ve bu ilișkilerin altında yatan mekanizmaları tam olarak açıklığa kavușturamamıștır. Günümüzün dijital teknolojisinin karmaşıkığı ve hızla gelişmesi, bu teknolojinin bilimsel araştırmalar için ortaya koyduğu zorluklar göz önüne alındığında, çocukların gelişimi üzerindeki potansiyel etkisini araştırmak ve etkili yolların yaratılmasına rehberlik etmek için geçmiş araștırmalardaki metodolojik boșlukların giderilmesi oldukça faydalı olacaktır.

\section{Karakterlerin Çocuklara Sosyal ve Duygusal Süreçlerine Etkisi}

Fantastik animasyon kahramanlarının çizgi filmlerde giderek daha fazla kullanılması çocuklardaki etkilerinin araștırılmasını gerektirmektedir. Bu tür animasyon kahramanlarının çocuklara cazip gelen özellikleri, daha dikkatli șekilde ele alınması sonucunu doğurmaktadır. Bu kahramanların çocuklardaki etkilerini nitel değerlendirmelerle sorgulamayı amaçlayan Carrick ve Quas (26), yaş aralığı 3-5 olan çocukların fantastik, korkutucu ve gerçek olayları "bu gerçek hayatta olabilir mi?" șeklinde yorumladıklarını ve ifade ettiklerini belirlemiștir. Bu durum çocukların görüntülerin fantastik veya gerçek durumunu ayırt edemediklerini, dolayısıyla verecekleri tepkileri ve meydana gelecek olumlu ve olumsuz etkileri izlememiz gerektiğini ortaya koymaktadır.

Özellikle uzun saatlerșiddet içerikli programlar izleyen çocuklarda saldırganlık düzeylerinin arttığı bildirilmiștir $(27,28)$. Şiddet ve korku barındıran çizgi film programları çocuklar açısından olumsuz sonuçları tetikleyebilir. Çünkü içerdikleri olumsuz durumlar çocukların güven duygusunu zayıflatabilir. Çocuklara kimseye güvenmemeleri gerektiğini ve tehlikeli olduklarını düșünmeyi öğretmektedir (17). Bu tür sorunların erken dönemde tespit edilerek gereken önlemler alınmadı̆̆ında problemlerin yetișkinliğe kadar devam edebildiği belirtilmiștir (29). Çocukların bu tür içerikleri en fazla televizyon programlarıyla takip ettikleri bilinmektedir (4). Bu gerçekten yola çıkarak yapılan çalıșmalarda ilerleyen dönemlerde televizyonun çocuklar üzerindeki etkileri araştııımıştır. Örneğin, Pagani ve arkadaşları (30), Wright ve arkadaşları (31), televizyon izlemenin uzun süreli etkileri olduğunu, erken çocukluk döneminde uygun olmayan içeriklere sahip programların izlenmesinin ergenlik dönemine kadar yansıyan sonuçları olabildiğini bildirmiștir. Hancox ve arkadașları (32), televizyon izlemenin okul yıllarını aşan ve yetişkinliğe kadar devam eden geniş kapsamlı sonuçlara sahip olabileceğini belirtmiștir. Bir müdahale çalıșmasının sonuçları televizyondaki içerikleri izlemeye harcanan sürenin azaltılmasının, ilkokul çocuklarında saldırgan davranıșları azalttığını göstermiștir (27). Verlinden ve arkadaşlarının (33), çocukların en çok izlediği iletişim araçlarından biri olan televizyonun izlenme miktarının, türünün ve örüntülerinin okul öncesi çocuklarda davranışsal sonuçlarla ilișkisini belirlemeye yönelik yaptığı çalıșmada, çocukların televizyon izlemek için oluşturdukları kalıpların daha çok erken çocukluk döneminde geliștiği ve bu kalıpların hayatlarının ilerleyen dönemlerinde devam etmesinin olası olduğu belirtilmiștir. Ayrıca, küçük çocukların sürekli olarak televizyondaki içeriklere maruz kalmalarının, dıșsallaştırma sorunlarının oluşma riskini arttırdığı ve önceden dıșsallaștırma sorunları olan çocukların, erken çocukluk döneminde yüksek televizyon izleme süreleri nedeniyle kalıcı sorunlar yaşama olasılıklarının daha yüksek olduğu belirlenmiștir. Yousef ve arkadașlarının (34), çalıșmasında da benzer sonuçlar elde edildiği bildirilmiştir. Günde iki saatten fazla televizyon içeriklerine maruz kalmanın ve video oyunları oynamanın, içe kapanma, dikkat sorunları ve saldırgan davranıșlarla ilișkili olduğu belirlenmiş̦tir. Çocuğun izlediği çizgi filmlerdeki șiddet içeren ve saldırı faktörünü öne çıkaran eylemler saldırgan duygu ve düşünceleri daha da arttırabilir. Bu durum bellekte yer alan ilgili düșünce, duygu ve kavramların etkinleștirildiği bir süreçtir (35). Sergilenen negatif davranıs ve duyguların fantastik kurgunun çocuklardaki şüpheciliğe yönelik eğilimleri arttırmasıyla da ilișkili olduğu belirtilmiștir. Samuels ve Taylor'un (16), çocuklara 
gerçek ve korkutucu fantastik olay görüntülerini izleterek hangi görüntülerin gerçek hayatla ilișkili olduğunu açıklamalarını istedikleri çalıșmada çocukların korkutucu fantastik görüntülerin gerçek hayatta olamayacağını belirttikleri, olayları kurgusal olarak yargılama eğiliminde oldukları, yüksek düzeyde sıkıntı yaşadıkları ve korku tarifledikleri belirlenmiştir. Çocukların özellikle olumsuz bir olay veya varlık tarafından duygusal olarak uyarıldıklarında olayları gerçek olarak algılayarak sorunlar yașayabildikleri görülmüştür. Bu konudaki diğer bir yaklașım da fantastik kahramanların ve ișlenen olumsuz içeriklerin kendi içinde algılanan bir gerçeklik olușturması, bunun da izleyicilerde olayların, ortamların ve karakterlerin gerçek dünyada var olduğu veya var olabileceği șeklinde algılanmasıdır. Çocuk televizyonda veya filmlerde gördüğü fantastik olaylara ne kadar çok inanırsa, algılanan gerçeklik derecesi o kadar yüksek olmaktadır. Algılanan gerçekliğin șiddetin etkisini belirlemede önemli bir faktör olduğu belirtilmektedir. İzleyici, gördüklerinin gerçek hayatta da olabileceğine ne kadar çok inanıyorsa, benzer saldırganlık eylemleri sergileme riski o kadar yüksek olacaktır (36). Genel olarak bu bulgular, maruz kalınan yaştan bağımsız olarak, olumsuz içeriklerin izlenmesinin çocukluk döneminde zararlı etkileri olabileceğini düșündürmektedir (20).

\section{Karakterlerin Çocuklardaki Olumsuz Etkilerinin Azaltılması}

1960’ların sonlarından itibaren çizgi film kaynaklı şiddetin etkilerini belirlemeye yönelik yapılan araștırmalarda aktif arabuluculuğun etkisi araștırılmıştır (37). Bu yöntem, șiddet içerikli yapımlar hakkında çocuklarla aktif olarak konuşma sürecini ifade eder. Aktif arabuluculuk sırasında, çizgi filmlerde tasvir edilen saldırganlık eylemleri hakkında "ne kadar yanlış bir harekettir", "vurmak veya șiddet uygulamak yanlıștır" ve "birini vurmak doğru değildir" gibi yorumlar yapılır (38). Bu sayede çocukların izledikleri çizgi filmlerden edinecekleri olumsuz davranışları taklit etme olasılığı azaltılabilir. Bu tür karșiıklı yapılacak konuşmalar ve düşünce alışverişleri, şiddet içeren içeriklerin izlenmesinden önce, izlenmesi esnasında veya sonrasında yapılabilir. Yapılan bazı çalışmalar bu yaklaşımın çocuklara hangi davranıșların kabul edilebilir olup hangilerinin kabul edilemez olduğunu iletmenin basit bir yolu olduğunu göstermiștir. Ayrıca çocuklar, şiddet içerikli çizgi filmleri izledikten sonra kendilerini daha saldırgan hissetseler bile, aile veya toplumdan alacakları cezadan kaçınmak için kendi davranıșlarını kontrol etmeleri gerektiğini de öğrenebilirler. Öte yandan çocukların çizgi filmlerdeki olaylar ve fantastik animasyonlardaki kahramanların sergilediği davranışların gerçeklik durumuna ilișkin yargıları özellikle de yașı küçük çocukları olayların gerçek dışı olduğunu düșünmeye yatkın hale getirmektedir. Bu durum yansıtılan karakterlerin gerçekçi olduğunu, tasvir edilen fantastik olayların gerçekten olabileceğini düșünme eğilimlerini arttırmaktadır. Dolayısıyla çocukların bu olaylarla ilgili deneyimleri arttıkça gerçek olayları ve gerçek dışı fantastik olayları olması gerektiği şekilde görmeye başlarlar (12).

\section{Sonuç ve Öneriler}

Özellikle okul öncesi çocuklar medya ve iletişim pazarının önemli bir hedef kitlesidir (28). Kurgulanmış içerikleriyle çizgi filmler ve fantastik animasyonlardaki karakterler çocuklar için ilgi çekici olabilmektedir. Literatürde yapılan çalıșma sonuçları çizgi filmlerin ve fantastik animasyonlardaki karakterlerin çocuklar tarafından sıklıkla takip edildiğini göstermiștir (4). Fakat bu tür içeriklerdeki gerçek ve fantastik olayların ayrımının çocuklar tarafından net olarak yapılamadığı belirlenmiştir. Yaş grubu 4-5 olan çocukların 7-8 yaşındaki çocuklarla karşılaştırıldığı çalışmalarda bu durum sonuçlara yansımış ve fantezi/gerçek ayrımının yaşla birlikte yavaş yavaş geliștiği belirlenmiștir (3). Medyanın çocuklara erișim amaçlı kullandığı televizyon programları içerisinde çizgi filmler ve bu filmlerin içerisinde yer alan farklı olumsuz içeriklere maruz kalmak küçük çocukların gelişimini, davranışlarını ve günlük aktivitelerini etkileyebilir. Bu tür içeriklere yüksek düzeyde maruz kalmanın okul öncesi çocuklarda, önceden dışsallaştırma sorunları olmayanlarda bile, dışsallaştırma sorunları meydana gelme olasııı̆ını arttırdığı belirlenmiștir. Bu bulgular dikkate alındığında çocukların olumsuz içeriklere karşı korunması gerekliliği ortaya çıkmaktadır. Bu bağlamda çizgi filmler çocukların yaşlarına, gelișim dönemlerinin genel özelliklerine uygun seçilmelidir. Amerikan Pediatri Akademisi'nin tavsiyelerinde de belirttiği gibi iki yaşından büyük çocuklara günde iki saatten az olacak şekilde, içeriği kaliteli programlar izletilmelidir (39). İçeriğinin ne olduğu bilinmeyen çizgi filmlerle çocuklar süresiz şekilde baș bașa bırakılmamalıdır. Ebeveynler çocuklarıyla etkileșimli oyunlar oynamalı ve onlarla kaliteli zaman geçirmeye önem göstermelidir. Farklı medya türlerinin küçük çocukların fantastik olaylara iliş̧in anlayışlarını belirlemek için daha fazla araștırmaya intiyaç vardır.

\section{Kaynaklar}

1. Woolley JD, Ghossainy ME. Revisiting the fantasy-reality distinction: children as naïve skeptics. Child Dev 2013; 84(5): 1496-1510.

2. Piaget J. The Child's Conception of Physical Causality. London: Routledge \& Kegan Paul, 1929.

3. Martarelli CS, Mast FW, Läge D, Roebers CM. The distinction between real and fictional worlds: investigating individual differences in fantasy understanding. Cogn Dev 2015; 36: 111-126.

4. Erdoğan S, Baran G. A study of parents regarding television watching habits of their children in the four-six age group. Soc Sci 2008; 3(3): 245-248.

5. Gonçalves S, Ferreira R, Conceição EM, et al. The impact of exposure to cartoons promoting healthy eating on children's food preferences and choices. J Nutr Educ Behav 2018; 50(5): 451-457.

6. Huston AC, Wright JC, Marquis J, Green SB. How young children spend their time: television and other activities. Dev Psychol 1999; 35(4): 912-925. 
7. Öztürk C, Karayağız Muslu G. Okul öncesi dönemdeki çocukların televizyon izleme durumları ve bunu etkileyen incelemesi. Milli Eğitim Dergisi 2007; 175: $116-128$

8. Kalan ÖG. Medya okuryazarlığı ve okul öncesi çocuk: ebeveynlerin medya okuryazarlığı bilinci üzerine bir araștırma. İstanbul Üniversitesi İletişim Fakültesi Hakemli Dergisi 2010; 1(39): 59-73.

9. Adak N. Bir sosyalizasyon aracı olarak televizyon ve şiddet. Bilgi Dergisi 2004; 30: 27-38.

10. Middleton $\mathrm{Y}$, Vanterpool SM. TV cartoons: do children think they are real. ERIC 1999; ED437207: 1-13.

11. Klein H, Shiffman KS. Messages about physical attractiveness in animated cartoons. Body Image 2006; 3(4): 353-363.

12. Li H, Boguszewski K, Lillard AS. Can that really happen? Children's knowledge about the reality status of fantastical events in television. J Exp Child Psychol 2015; 139: 99-114.

13. Bourchier A, Davis A. Individual and developmental differences in children's understanding of the fantasy-reality distinction. Br J Dev Psychol 2000; 18(3): 353-368.

14. Bourchier A, Davis A. The influence of availability and affect on children's pretence. Br J Dev Psychol 2000; 18(1): 137-156.

15. Sayfan L, Lagattuta KH. Scaring the monster away: what children know about managing fears of real and imaginary creatures. Child Dev 2009; 80(6): 1756-1774.

16. Samuels A, Taylor M. Children's ability to distinguish fantasy events from real-life events. Br J Dev Psychol 1994; 12(4): 417-427.

17. Ekici FY. Çizgi filmlerin çocuklar üzerindeki etkilerine ilișkin çok boyutlu bir değerlendirme. Türk-İslam Dünyası Sosyal Araștırmalar Dergisi 2015; 2(5): $70-84$.

18. Akyüz E. Çocuğun Bilgi Edinme ve Zararlı Yayınlara Karșı Korunma Hakkı. I. Türkiye Çocuk ve Medya Kongresi Bildiriler Kitabı, 2013: 115-132.

19. Mares M-L, Pan Z. Effects of Sesame Street: a meta-analysis of children's learning in 15 countries. J Appl Dev Psychol 2013, 34(3): 140-151.

20. Kostyrka-Allchorne K, Cooper NR, Simpson A. The relationship between television exposure and children's cognition and behaviour: a systematic review. Dev Rev 2017; 44: 19-58.

21. Christakis DA, Zimmerman FJ, DiGiuseppe DL, McCarty CA. Early television exposure and subsequent attentional problems in children. Pediatrics 2004; 113(4): 708-713.

22. Nathanson Al, Aladé F, Sharp ML, et al. The relation between television exposure and executive function among preschoolers. Dev Psychol 2014; 50(5): 1497-1506.

23. Shin N. Exploring pathways from television viewing to academic achievement in school age children. J Genet Psychol 2004; 165(4): 367-382.
24. Baydar N, Kağitçibași Ç, Küntay AC, Gökșen F. Effects of an educational television program on preschoolers: variability in benefits. J Appl Dev Psychol 2008; 29(5): 349-60.

25. Roberts DF, Bachen CM, Hornby MC, Hernandez-Ramos P. Reading and television: predictors of reading achievement at different age levels. Commun Res 1984; 11(1): 9-49.

26. Carrick N, Quas JA. Effects of discrete emotions on young children's ability to discern fantasy and reality. Dev Psychol 2006; 42(6): 1278-1288.

27. Robinson TN, Wilde ML, Navracruz LC, Haydel KF, Varady A. Effects of reducing children's television and video game use on aggressive behavior: a randomized controlled trial. Arch Pediatr Adolesc Med 2001; 155(1): 17-23.

28. Özmert EN, Ince T, Pektas A, Özdemir R, Ückardes Y. Behavioral correlates of television viewing in young adolescents in Turkey. Indian Pediatr 2011; 48(3): 229-231.

29. Huesmann LR, Moise-Titus J, Podolski C-L, Eron LD. Longitudinal relations between children's exposure to TV violence and their aggressive and violent behavior in young adulthood: 1977-1992. Dev Psychol 2003; 39(2): 201-221.

30. Pagani LS, Fitzpatrick C, Barnett TA, Dubow E. Prospective associations between early childhood television exposure and academic, psychosocial, and physical well-being by middle childhood. Arch Pediatr Adolesc Med 2010; 164(5): 425-431.

31. Wright JC, Huston AC, Murphy KC, et al. The relations of early television viewing to school readiness and vocabulary of children from low-income families: the early window project. Child Dev 2001; 72(5): 1347-1366.

32. Hancox RJ, Milne BJ, Poulton R. Association of television viewing during childhood with poor educational achievement. Arch Pediatr Adolesc Med 2005; 159(7): 614-618.

33. Verlinden $\mathrm{M}$, Tiemeier $\mathrm{H}$, Hudziak JJ, et al. Television viewing and externalizing problems in preschool children: the generation $r$ study. Arch Pediatr Adolesc Med 2012; 166(10): 919-925.

34. Yousef S, Eapen V, Zoubeidi T, Mabrouk A. Behavioral correlation with television watching and videogame playing among children in the United Arab Emirates. Int J Psychiatry Clin Pract 2014; 18(3): 203-207.

35. Kirsh SJ. Cartoon violence and aggression in youth. Aggress Violent Behav 2006; 11(6): 547-557.

36. Bandura A. Influence of models' reinforcement contingencies on the acquisition of imitative responses. J Pers Soc Psychol 1965; 1(6): 589-595.

37. Hicks DJ. Effects of co-observer's sanctions and adult presence on imitative aggression. Child Dev 1968; 39(1): 303-309.

38. Cantor J, Wilson BJ. Media and violence: intervention strategies for reducing aggression. Media Psychol 2003; 5(4): 363-403.

39. American Academy of Pediatrics. Children, adolescents, and television. Pediatrics 2001; 107(2): 423-426. 